\title{
NICANOR PARRA EL RIESGO DE ANTESCRIBIR
}

\section{Eduardo Milán}

La publicación de Poemas y antipoemas en 1954, entre muchos efectos, rompió con lo que el autor de este ensayo define como "el lugar de esperanza" en que se había instalado la poesía latinoamericana hasta la mitad del siglo XX. Para Milán, poetas como Vallejo, Huidobro o Neruda escribían desde —o sobre - un lugar mítico, utópico al que los pueblos latinoamericanos llegarían luego de un largo camino de sometimiento y sufrimiento. Parra, sin embargo, devuelve la poesía al hombre igual a todos y desde allí, por lo tanto, devuelve la poesía a la comunidad, en un gesto desafiante y, también, prometeico.

The publication of Poemas y antipoemas in 1954 pierced what the author of this article defines as the "place of hope" where Latin American poetry had taken refuge through the first half of the 20th century. For Milan, poets like Vallejo, Huidobro or Neruda wrote from - or about - a mythical, utopian place that the Latin American peoples would reach after a long journey of submission and suffering. Parra, however, returned poetry to the ordinary man and, as a result, he gave poetry back to the community in a defiant, yet also Promethean, gesture.

Eduardo Milán (Montevideo, 1952). Poeta y ensayista uruguayo. Reside en México desde 1979. Fue miembro del consejo de redacción de la revista Vuelta, que dirigió Octavio Paz, y del Sistema Nacional de Creadores de Arte. Recientes publicaciones, poesía: Disenso (México: Fondo de Cultura Económica, 2010), Vacio, nombre de una carne (Montevideo: HUM, 2011); ensayo: Ensayos Unidos (Madrid: A. Machado Libros, 2011), No hay, de veras, veredas (Madrid: La Resistencia, 2012). Email: anfibiodiez@gmail.com 
1.

\section{Eso que es la antipoesía}

on el término "antipoesía" se pone en juego algo en el lector a
quien parecería que se le viniera abajo el mundo, el mundo de la poesía. Eso ocurrió y no ocurrió. Pero en 1954. Y en el Chile de Nicanor Parra con la publicación de Poemas y antipoemas. Es el mismo Parra quien en "Advertencia al lector", uno de sus textos más celebrados, remite a una probable perturbación que su poesía habría causado a ciertos críticos, a los que llama en ese texto "doctores de la ley". ${ }^{1}$ Claro que una cosa es el grito en el cielo en 1954. Otra, muy otra, la puesta en el cielo del grito hoy. Todo ha pasado bajo el agua del arte. Empezando por el arte. De manera que no habría de qué sorprenderse cuando alguien habla de antipoesía. ¿Acaso no se habló hasta el cansancio de antiarte desde comienzos del siglo XX? Pero en la tardía - por demorada, no por vieja - América Latina el efecto estético tenía la característica de ocurrir después que en las llamadas metrópolis, nombre que, en términos de anticipación o de "estar al día", cedió lugar al nombre más técnico y más real de "productoras de información de punta", cosa que define mejor el lugar de esas urbanizaciones donde durante el siglo XX (y antes ya entrado el XIX) se repartía novedad y preceptiva a diestra y siniestra mundiales.

\section{Un espacio desafiante}

¿Se podría hablar en plena globalización de los lugares "relegados" (parece haber un cierto eufemismo en la palabra que obliga a las comillas) históricamente —o con cierta deuda histórica en relación a sí mismos, no tanto en relación a la modernidad o, mejor, a la modernización- como lugares de esperanza? En términos de transformación social sin duda. Chomsky, entre otros, llamó la atención sobre esta convicción. Pero me refiero a estos lugares "relegados" como posibles - o imposibles-, lugares de esperanza artística. El argumento es relativamente simple. El proceso moderno que arranca en el siglo XVIII y da lugar a la mundialización presente habría, con sus reiteradas crisis, ago-

${ }^{1}$ Nicanor Parra, Poemas y antipoemas en Obras completas \& algo $+/$ Vol. I (Barcelona: Galaxia Gutenberg - Círculo de Lectores, 2006). 
tado las baterías críticas del arte y de la estética. Agotado en este sentido: no hay ninguna perturbación o inquietud social o civilizatoria en las sociedades postindustriales - las de un capitalismo postindustrial hiperdesarrollado, crisis financieras incluidas - en relación al arte. El arte no es materia de interés más que para especialistas. O para interesados de una cierta jerarquía crítica. Lo demás es industria cultural y mercancía masiva para consumidores formados por el propio mercado al que los consumidores todavía creen que dirigen. El tema interesa en la medida en que se concretan problemas específicos - cae el techo de una capilla pintada en el siglo XVIII, desaparecen cuatro Picassos, muere Stockhausen - y se lo recuerda, se lo encuadra y reconduce a su lugar en la altura. Pero en América Latina, lugar no homogéneo socialmente y sí con el deseo viable de ganar autonomía, sobre todo en el sur, el arte era, en 1950, un lugar de esperanza porque estaba directamente vinculado a una cierta idea utópica de sociedad pasible de existencia transformada. La idea de este arte conductor de esperanza o trabado en ella se pone en jaque cuando, por ejemplo, en poesía, "arte de la palabra", se le planta adelante su aparente antítesis: la antipoesía. ¿Puede la antipoesía, formulada así — no en un estricto sentido parriano - como antítesis poética ocupar un lugar en un proyecto de esperanza? La antítesis tiene signo negativo. Y aunque la Escuela de Frankfurt plantee en su teoría crítica el hilo conductor de la negatividad como principio dialéctico — no sólo ético - de cara a la realidad social del mundo capitalista contemporáneo, en poesía y en América Latina la apuesta por una "negatividad" vinculada a lo poético parece poco menos que un contrasentido, un sinsentido o una burla. La poesía latinoamericana participó del fenómeno europeo de las vanguardias estético-históricas. Vicente Huidobro, César Vallejo, Pablo Neruda, Emilio Adolfo Westphalen, José María Eguren, César Moro, para nombrar a los más conocidos de la primera época vanguardista latinoamericana, son titulares de escrituras en una parte importante vinculadas a las vanguardias europeas. Pero ninguna de esas escrituras - excepción de excepciones es el caso de Huidobro, merece ser explicado - postula un signo negativo. En realidad, no postula ningún signo. Hay que desentrañar filiaciones o desafiliaciones en cada caso. Sólo en movimientos orgánicos (martinfierrismo argentino, estridentismo mexicano, para citar dos casos singulares) se postula un ideal de independencia creativa o de transformación de poesía y sociedad. Pero negatividad, ni por asomo. El caso excepcional —y paradóji- 
co- de Huidobro resalta, extremo. Aunque Huidobro se autocalifica en el prefacio a Altazor "antipoeta y mago", el signo bajo el cual inscribe la particular aventura de ese libro es más un signo des-constructivo que una negatividad. Huidobro, en el mejor de los casos, niega in totu la poesía teóricamente, pero la afirma lingüísticamente. Y lo hace hasta sus últimos días, como lo testimonia este fragmento de carta a Juan Larrea:

Nosotros somos los últimos representantes irresignados de un sublime cadáver. Esto lo sabe un duendecillo al fondo de nuestra conciencia y nos lo dice en voz baja todos los días. De ahí la exasperación de nuestro pecho y de nuestra cabeza. Queremos resucitar el cadáver sublime en vez de engendrar un nuevo ser que venga a ocupar su sitio. Todo lo que hacemos es ponerle cascabeles al cadáver, amarrarle cintitas de colores, proyectarle diferentes luces a ver si da apariencias de vida y hace ruido. Todo es vano. El nuevo ser nacerá, aparecerá la nueva poesía, soplará en un gran huracán y entonces se verá cuán muerto estaba el muerto. El mundo abrirá los ojos y los hombres nacerán por segunda vez, o por tercera o cuarta. ${ }^{2}$

Lo que parece despuntar, entre todo esto, es una certeza: la negatividad para los poetas y muy especialmente para los poetas latinoamericanos se asimila a "cosa teórica", no práctica. Es territorio de la idea negar prácticas, el de la escritura es afirmarla. Esto disocia peligrosamente pensamiento y escritura. $\mathrm{O}$ inscribe a la escritura poética en un ámbito de "cosa no pensada", casi una mística, o proveniente de un dominio ya pensado: el mito. No sólo en 1954 cuando se presenta la antipoesía. Todavía ahora.

\section{Parra, por más datos}

La poesía de Nicanor Parra, la "antipoesía", fue tomada desde su "presentación en sociedad" como un cuerpo extraño al espacio poético latinoamericano, espacio histórico-estético concebido entonces como lugar de esperanza.

${ }^{2}$ Vicente Huidobro, "Carta a Larrea" en el álbum de la "Antología” publicada en Poesía, revista ilustrada de información poética, números 30, 31 y 32, Madrid, 1989, 389-390. 
Dos envíos de la poesía de Parra plantean el cuestionamiento. El primero, una acusación: la poesía presente en 1950 es una poesía de "vaca sagrada", una poesía de discurso autosacralizado, escrito en un modo alejado del lector común. A esta poesía "dominante" se la refiere como aquella poesía al mismo tiempo retóricamente dominada por un empaste metafórico denso, arbitrario (habría que volver sobre el mínimo o escasísimo uso de la metáfora en Parra), cuya lógica es un cultivo de esa especificidad lingüística totalmente autista. La complicidad del lector tiene que ser evidente: lo acepta "encantado". Raíz de encantamiento, lo que vincula y atrapa al lector es la apertura de mundos, la posibilidad de una existencia otra, el descubrimiento de la maravilla. La imagen es el vehículo de suplantación de la realidad del habla no imagística. Dispara en el lector una necesidad —o una voracidad - generativa en el nivel de la población de mundo. Si se observa desde este ángulo, la poesía de Neruda, para seguir con el paradigma dominante, es, a partir de Canto general, una poesía de escaso vacío: el mundo se reduce - en realidad, se expande - en base a una imagen de completitud que se da, precisamente, por imagen. Se crea la ilusión de la "riqueza del mundo" que no viene a ser otra cosa que una riqueza imaginaria. Esta ilusión va tomando la visibilidad del lector hasta cubrir el espacio completo de su percepción generativo-constructiva de imágenes. Aunque el proceso poético mental considera la creación de visualidad por generación de protoimagen; o sea, por elaboración mental de la imagen, la modernidad sustituye la protoimagen por la imagen constituida: hay una dominación por la imagen, una imposición imaginaria. El poema, visto en esta perspectiva, trabaja a imagen $d a d a$. La imagen dada es fácil de consumir. En términos de complejidad, la imagen que produce el signo es la menos compleja, mientras que la metáfora constituye un alto grado de complejidad: hay que procesar mentalmente lo que la metáfora en su desplazamiento intercambia. El juego de espacios que la metáfora propone compone sí una otredad para el lector. Este proceso, altamente creativo, se olvida en la poesía que se abre con la modernidad y que empieza en el siglo XVIII. El lector de poesía quería, hasta entrada esa última fase moderna, que se le abrieran mundos. La poesía trabajaba - hasta el barroco inclusive, siglos XVI y XVII- a mundo cerrado. El devenir de esa modernidad, extremadamente convulsiva por los ingredientes que porta el activado concepto de revolución (Revolución 
Francesa, Revolución Industrial, revolución socialista, revolución tecnológica y, también, revolución artístico-estética, todo junto y apenas entrada la última fase moderna), parece obligar a la práctica artística - y la poesía es tocada hondamente por estos procesos - a un doble movimiento no paralelo: primero, a una crisis en su propio ser - como deudora de su autoconciencia y de su autonomía conquistada en el siglo XVIII- y, luego, a una simplificación en sus procedimientos. Para el lector medio, lector de poesía, ese espacio que se le abre lo dignifica como ser sensible. El concepto de aura protege al mismo tiempo a autor y receptor: el autor se sublima a sí mismo, el receptor se trasciende. Pero al simplificarse el acceso al objeto poético baja el nivel de dignificación del lector. Este es un fenómeno gradual que, con altibajos - no se puede poner a Baudelaire, Rimbaud, Mallarmé, Laforgue, Corbiére, Rilke y luego a varios exponentes de la radicalidad vanguardista en este saco-, llega al siglo XX y lo atraviesa. En 1954, la crítica que abre la poesía de Parra camina, en el sentido antes señalado, por un borde muy difícil. El lenguaje coloquial es un lenguaje que no sale del circuito —o sale muy poco - de lo reiterativo. Sería, calibrado en sus niveles de intensidad, un lenguaje previsible. Hay poco que, en términos de invención lingüística, esperar de él. El uso del lenguaje coloquial varía a través del tiempo: un uso le da un poeta provenzal como Guillaume de Peitieus en el siglo XI, un uso le da la poesía popular del romancero medieval, otro uso le da François Villon en la misma época, otro Jules Laforgue, a quien se considera el introductor consciente — es decir, casi programático en su radicalidad - de la coloquialidad, en el siglo XIX, en la poesía de la última fase moderna. Los distintos empleos están directamente vinculados a la experiencia vital en los casos citados - un poco menos en el de Laforgue-, es un lenguaje que intenta que la poesía sea expresión más o menos directa de la vida, su prolongación, si se quiere. La crítica propuesta por la antipoesía de Parra no termina con el índice puesto en el abaratamiento retórico que padece el lenguaje poético en su momento histórico. Si se tratara sólo de lenguaje coloquial reactivado, la poesía de Parra hubiera necesitado - lo necesitó, de hecho - una labor de discernimiento fino para no ser confundida en el uso de lenguaje con una legión de versificadores. El índice de la otra mano apunta a cualquier intento o propósito de una poesía experimental. Se debe hacer notar que la crítica de Parra a una poesía experimental (se 
refiere a una cierta vanguardia gastada por incomprendida: la surrealista, a la que Parra considera una poesía fantasiosa, decorativa y que nada tiene que ver con la realidad, cosa que es cierto, pero esto último puede no ser simple demérito) cierra la posible escapatoria de lo ornamental decorativo. Hay una posibilidad siempre abierta de destrucción, como crítica radical, al objeto poético. La crítica a la vanguardia que hace Parra (aunque sea a una vanguardia débil en relación a su visión del mundo real como la surrealista, al borde siempre de pasar de ser una vanguardia de la imagen a una vanguardia imaginaria) bastaría para apartarlo de toda vinculación a una poética de la negatividad. Una poesía decorativa como la nerudiana desde Canto general construye ornamento. Una poesía de vanguardia lo destruye. La clave es el medio, el común con el que Parra identifica al lector.

El segundo envío es la propuesta de devolución de la poesía a su verdadero dueño: el hombre igual a todos. Esta devolución (como si el lenguaje hubiera sido secuestrado por bandos rivales que se disputaran el control del espacio poético latinoamericano) sólo puede ser llevada a cabo en la práctica de una poesía cuyo lenguaje es el lenguaje de todos los días. ¿En qué se enfrenta una actitud semejante a la de Parra con la concepción de un espacio poético concebido como lugar de esperanza? En que ese lugar de esperanza es un lugar mitificado, idílico. Lo que se descubre si se levanta el velo por completo es lo siguiente: debajo de ese lugar de esperanza, lugar de promesa, hay no sólo la identificación de un espacio utópico. No olvidar, Canto general de Pablo Neruda consideraba la siguiente simetría de carácter mesiánico (oculto) para la historia latinoamericana: la capacidad de sufrimiento, de traición, de derrota, de sometimiento sufrida por los pueblos latinoamericanos es la garantía de su futuro liberado. Para sorpresa del propio Neruda, que no era precisamente un hombre religioso en el sentido de una ortodoxia cristiana y menos católica, lo que se adivina aquí es una razón proporcional muy parecida a la del cristianismo redentor: a mayor penuria terrenal, mayor garantía de ganar la otra vida. Pero lo más espinoso o grave se observa desde el punto de vista del lenguaje poético. No sólo se considera ese proyecto utópico como lugar de esperanza: se escribe en un lenguaje utópico en correspondencia con ese lugar. Se quiso hacer equivalente el espacio de un deseo a un lenguaje de un deseo. Dicho de otro modo, se escribía en futuro. Hay que subrayar aquí la singular 
coincidencia entre el lenguaje metafórico-decorativo — cuyo ejemplo más logrado es Neruda - y el lenguaje descarnado, a veces puramente denotativo, no antipoético sino a-poético de la poesía de los años sesenta y setenta en América Latina, que se conoce con el nombre infeliz de "poesía comprometida". Aunque en extremos opuestos, en relación a su aparato retórico, ambas posturas apuntan a lo mismo: escribir el futuro ahora. De lo que carecen las dos propuestas es de presente. Es lo que quiere devolver Parra a la poesía. Aunque esto suene como un atentado al mejor imaginario, el imaginario prospectivo. Y aunque la "fase Canto general" de Pablo Neruda fuera producto renegado - él lo llamaba realista - de un autorrechazo, el de la "fase residencial" de su poesía (Residencia en la tierra $I$ y II) es un momento de gran profundidad lírica y de igual riesgo lingüístico, que lo situó al borde de un incomunicable pocas veces alcanzado en la poesía latinoamericana. Neruda rechaza ese incomunicable movido, entre otras causas, por la circunstancia histórica que lo acosa y lo hace definirse en ese momento: la Guerra Civil Española (1936-1939), experiencia crucial histórica para Europa y para el mundo, y ensayo de autoritarismo fascista que comenzaba ya a dominar Alemania e Italia por entonces. En esa guerra muere su gran amigo Federico García Lorca. Neruda no intuye —o lo intuye y lo desoyeque la circunstancia histórica que ordena la realidad es válida para esa realidad y para la experiencia humana solidaria y participativa. No necesariamente para la poesía. Neruda diluye en términos de información estética lo que ha aprendido en Residencia en la tierra. El resultado de ese rebajamiento de intensidad es una poesía de imaginario decorativo que juega con una verdad a priori — la certeza histórica - desplazada al terreno de la escritura, territorio de la tentativa. Ese a priori histórico - en el caso de la poesía que escriben desde los años cuarenta en América Latina Neruda y otros- es el que late bajo el concepto de espacio estético como lugar de esperanza. Habría que confiar en que en algún momento el lugar de esperanza coincidente con el espacio poético no fuese el espacio deudor de la fatalidad histórica. El lenguaje poético ganaría en movilidad; Vallejo diría, "intensidad y altura". Siempre queda la duda de si Parra renuncia al lugar de esperanza o al lenguaje poético que deriva de ese lugar de esperanza cuando es tomado como obligación y preceptiva moral. De cualquier manera, un lugar de esperanza es un lugar acotado, reservado. Parecería lo contrario de un lenguaje del 
fluir, del movimiento, como es el lenguaje cotidiano. El gran desafío sería transformar el lenguaje común en el lugar de esperanza. Parece ser la apuesta, lo reconozca o no Parra, de una antipoesía como la suya. Lo cierto es que un corte en la historia de la poesía latinoamericana practicado durante la aparición en 1954 de Poemas y antipoemas muestra una identificación de crítica y lector de la actitud de Nicanor Parra, con una apuesta por un anti-lugar de esperanza. Fueron necesarios muchos deslindes y reiterados reconocimientos de poetas de generaciones más jóvenes — que bordeaban, en general, por fecha de nacimiento los años cincuenta- que aprendieron de Parra (Juan Luis Martínez, Raúl Zurita, Diego Maquieira, Paulo de Jolly, entre otros) para re-virtuar el lugar real de esa poesía. Hoy es posible acercarse a esta poesía sin el temor amenazante de una posible negatividad embozada (que, por cierto, gran parte de una poesía profunda en tanto que aventura verbal manifiesta en el siglo XX) ni tampoco con la sospecha de que la aventura parriana esconde una especie de traición al espacio utópico latinoamericano.

De los dos envíos críticos de la poesía de Parra a la actitud del contexto poético en que se inscribirá su propuesta resalta la segunda, la idea de una devolución, de una restitución al lector de lo que la poesía sería esencialmente: lenguaje del hombre común, el lenguaje del común, el lenguaje común. La idea teórica de Parra contesta, en un primer lugar de complejidad, lo recibido por el arte occidental luego de la Ilustración. Sobre todo, contesta la idea de un arte autónomo, no dependiente de ningún ámbito fuera de sí mismo. Parra rechaza la autonomía del arte ahí donde ella propone el cultivo de la especificidad del lenguaje de cada disciplina artística. El cultivo del lenguaje específico de cada arte no presupone ningún tipo ni calidad de receptor. Más bien, no puede tomarlo en cuenta. Si la idea de especificidad significa que el arte se obedece, en las derivas que pueda tomar, sólo a sí mismo, la demanda de un lector quedaría fuera de juego. Hay que tomar en cuenta que a mediados del siglo XX ya había transcurrido buena parte del sobresalto producido por una práctica del arte, la europea occidental y sus derivados, que llevó al límite las posibilidades de un arte específico y consideró, incluso, la idea de una desaparición del arte. Parra, en relación al instrumental lingüístico que le proporciona el lenguaje de la conversación, se parece mucho a la propuesta de Marcel Duchamp en relación a los objetos. Al negar una diferencia específica entre objeto de 
arte y objeto común, Duchamp devuelve la práctica artística al terreno de lo dado. El tipo de objeto que crea, el ready-made, en realidad, un "objeto encontrado" más que un objeto creado, pertenece al dominio del uso, no al del arte. Parra parece trabajar en la misma línea conceptual. Esa sección de su poesía llamada Artefactos tiene como sustento teórico lo dado: son extracciones de un espacio común de objetos que por una razón u otra el poeta elige. Hay, en los Artefactos de Parra, como en el ready-made de Duchamp, un desplazamiento de la categoría de artista-creador a la categoría de artista-selector. La propuesta no sólo es compleja: es también utópica. Supone un ideal de comunidad a la que se le restituye su lenguaje: el lenguaje común. Y si la poesía es parte de ese lenguaje común del hombre común, la poesía es parte del lenguaje de la comunidad. En términos míticos el lance sería completo: la poesía es el lenguaje original de la comunidad. En 1950 se identificaba comunidad - el común - como el espacio de la igualdad. O sea: no sólo el espacio de todos, sino el espacio de todos iguales. Ésa era la idea de la poesía que escribía el lenguaje de esperanza en el lugar de esperanza. Esta coincidencia entre espacios no es necesariamente una coincidencia entre lenguajes. De ahí la perturbación que provoca la antipoesía considerada en su momento una especie de sabotaje. Es que el problema de la poesía va más allá del lenguaje: es una mitopoética la que alimenta el acto de poetizar. Las vanguardias, en un devenir que arrancaba en el siglo XIX, quisieron advertir sobre el peligro de una mitificación del acto poético. Una mitificación que operaba en la práctica como territorio de consuelo de una clase, la burguesía decimonónica, que necesitaba ser "salvada" de su propio horror. Al identificar mito y consumidor, la respuesta de la vanguardia radical fue acabar con el arte. Hay algo similar en la propuesta por rescatar el lenguaje común a la poesía de manos de un imaginario dominante, el mitopoético consumido por una clase dominante, y entregárselo a los "comunes". Notar que el gesto es el mismo gesto prometeico. Sólo que los dioses son identificados por Parra con aquellos poetas que llevaron al paroxismo la especificidad del lenguaje poético. Esa especificidad deriva inmediatamente de una consideración de la poesía como arte especial; es decir, fuera de lo común, extraordinario. La concepción está en Huidobro y en Neruda. Pero también en Vallejo. La penuria vital de Vallejo lo coloca en posición ventajosa ante Huidobro y Neruda, poetas que gozaron en vida de 
un reconocimiento a su especialidad. Pero en el caso de Vallejo, aunque reconocido por sus pares como un poeta mayor, su condición vital penosa lo condena a una exclusión del goce específico del poeta especial: la fama y su capital simbólico. Lo que Parra propone - y la crítica ve como sabotaje - es un desmontaje de la operación mítica en que la poesía latinoamericana en 1950, pasada la revolución vanguardista radical que prometía una disolución del arte en la praxis social - sobre todo en Europa-, todavía se encuentra. Probablemente los espacios, lugar de esperanza y comunidad como lugar, se parezcan o puedan, incluso, coincidir. Pero los lenguajes que sostienen esos espacios, los lenguajes que hablan esos espacios, son muy diferentes. El primero es parte de una operación de sublimación. El otro, de una operación deconstructiva de esa idealización.

\section{2.}

En la época de la demanda de hipercomunicación, el poema escrito en lenguaje extremamente conversacional como el del último Nicanor Parra - me refiero aquí al de "Discurso de Guadalajara" en adelantepuede correr el riesgo de descaracterizarse como aventura transformadora. La apropiación desde el siglo XIX, vía Jules Laforgue, de lo que se llamó posteriormente coloquialidad poética —un lenguaje muy parecido al lenguaje de una conversación común, no ya la "conversation between inteligent men" que diagnosticara erróneamente Ezra Pound que serían, como complejidad, sus The Cantos en un futuro; es decir, una conversación habitual, nada extraordinaria - significó más que un triunfo. También significó un comodín al que acudir para sacar al poema de situaciones de crisis y encrucijada. Esta fue la situación del poema en el siglo XX luego de la puesta en quiebra del papel que representaban las vanguardias estético-históricas en Europa desde 1910 a 1930 $\mathrm{y}$, radicalmente modificadas luego en su actitud, en territorio norteamericano. Un poema que, enmarcado en el ámbito general del arte, venía cargando del siglo anterior con un peso de "muerte" - la "muerte del arte", prevista en el Hegel de las lecciones de estética de 1828, es una de las contribuciones decisivas para la actitud crítica en los movimientos de vanguardia del siglo XX-y que, como ese arte con demanda es- 
pectral, quería consumarse en su disolución en la praxis social, ${ }^{3}$ sólo podría considerarse como cuerpo realmente extraño dentro de la cultura occidental dominante en tanto modelo sistémico, o como cuerpo más que extraño, como un sobrante de una crisis que no alcanzó, en su capacidad de reificación el espacio artístico-estético. La realidad de la poesía que se mide en el contexto mundial de la vanguardia y sus resonancias en América Latina — no los ismos latinoamericanos: los poetas individuales - sufrió el embate de una crisis que hizo, en un par de ejemplos concretos memorables, rever y modificar posturas que defendían un alto grado de realización poética o, como dice Roman Jakobson, de "temperatura estética". ${ }_{4}^{4}$ En los dos casos, el de Neruda y Vallejo, el cambio de actitud artístico-estética puede ser o no responsabilidad de la historia —el impacto de la Guerra Civil Española en ambos- Me refiero, es obvio, al cambio en la actitud individual y en la propuesta lingüístico-poética de Neruda en el transcurso de Residencia en la tierra II a Tercera residencia, en especial al capítulo "España en el corazón" y al fragmento "Explico algunas cosas". Y en el caso de César Vallejo también, es obvio, me refiero al salto descomunal entre la poética de Trilce y la de los Poemas humanos. Pero hay también ahí, en los dos casos y ya en la materia poética misma, una demanda de "comunicabilidad" que se desprende de la propia lógica epocal en la que se ve inmerso el lenguaje poético: la lógica que asimila realismo y humanidad, tomados como emblemas de un momento que pide a los seres humanos cercanía, solidaridad, intercambio; es decir, afecto. La "afectivización" (la palabra no existe, pero es eficaz en su ruido) de la poesía es el contragolpe evidente de una cultura artística que había soportado de sus operadores y actores un desprecio comunicativo y un desapego digno de encono. Nada se resolvió luego del planteo de la década de los sesenta del siglo XX sobre el lugar del arte en relación a sus posibles consumidores. Lo que resultó fue un arte que concedió lo más que pudo a la demanda de su lector, el arte de hoy. En este contexto, el surgimiento de Nicanor Parra en el ámbito poético latinoamericano a principios de la década de los cincuenta enfrenta varias oposiciones. Si se mira bien, al Neruda que enfrenta no es al Neruda, de ese presente, el de Canto ge-

\footnotetext{
${ }^{3}$ Peter Burger, Teoría de la vanguardia (Barcelona: Península, 1997).

${ }^{4}$ Roman Jakobson, Ensayos de poética (México: Fondo de Cultura Económica, 1982).
} 
neral. Enfrenta al Neruda de las Residencias. Es obvio que el Neruda realmente radical está en ese lenguaje enfrentado a un límite del decir poético iluminador desde su enrarecimiento comunicativo y también insólito en la poesía latinoamericana anterior. Neruda escribe contaminado de la mejor poesía del momento, la de Poeta en Nueva York (1929) de Federico García Lorca, con quien intercambia afinidades electivas, y de un cierto aliento órfico de escasa felicidad en la poesía latinoamericana. Esto último es válido, me parece, para cualquier fragmento temporal en que se considere a la poesía latinoamericana: aquí, al menos en poesía, prima la luz sobre la oscuridad, el deseo de superficie - aun de evidencia - sobre el ocultamiento. Sin embargo, nada dice que en arte la comunicación estética - densa, opaca - tenga alguna relación de dependencia de la comunicación de información común, clara y transparente. Teóricamente, ambas parecen oponerse. ${ }^{5}$ Ése es el posible referente de un señalamiento escritural de "tablas viejas devueltas por el mar" que Parra señala en "Manifiesto" como caracterización de la escritura de sus antecesores inmediatos. La línea condensa en una imagen lo que no funciona en poesía, eso que hasta el mar — que todo lo tragadevuelve y que no sirve ni como desecho por su consistencia ya perdida. También ciertos recursos de los repertorios de las vanguardias se volvieron padecimiento retórico; en especial, esa capacidad recursiva de la retórica de plantear formulaciones lingüísticas que parecen estar sucediendo en otro mundo. Hay en Parra, como en la poesía que Parra libera, una necesidad de hablar de lo que ocurre aquí y ahora. La vanguardia a la que se enfrentó Parra tenía algo en común con la "poesía comprometida" de los años sesenta: si la poesía comprometida escribía desde una certeza y no sólo hacia - lo que es comprensible y coherente- un lugar de esperanza, como dije arriba, la vanguardia ejercía en su presente una forma de esperanza que no encontró su espacio. Hay en ambas concepciones escriturales una sola y misma crisis, la del receptor, planteada en dos momentos: en la concepción de la vanguardia, en la falta de recepción presente para esas formas que deberían abrir futuro a un hombre distinto y, en la concepción de la poesía "comprometida", en una complicidad de recepción que, salvo excepciones, hacía desaparecer la transmisión estética. Lo interesante, en el planteo teórico del

\footnotetext{
${ }^{5}$ Jakobson, Ensayos de poética, 76.
} 
Parra que inicia con Poemas y antipoemas, es que se pone en posición de quien escribe entre esas dos aguas, la del rechazo del receptor y la de la complicidad del receptor, pero con una voluntad de unificar las aguas en beneficio del mismo lector, uno solo. Es sin duda una tentativa de redistribución poética o de una devolución de bien simbólico a quien le pertenece realmente, ese "hombre de la calle". La contradicción que lleva consigo la tentativa de Parra es la que hizo caer a Ezra Pound en la sobrevaloración del lector. Es un problema de discernimiento. El lenguaje que habla ese hombre de la calle en nombre de quien se redistribuye la energía poética de una época precisa y convulsiva, como la de los años cincuenta del siglo pasado, es también un lenguaje normativo. Oswald de Andrade lo llamaba "contribución millonaria de todos los errores". ${ }^{6}$ Es cierto, en la medida en que se tome error como sinónimo de pluralidad y alternativa, como diferencia y se haga cargo de una suerte de realidad entrópica creada por la acumulación. Es decir, en términos hegelianos, que la cantidad se vuelva calidad. Si no es así, lo que sucederá es la creación de un área franca de confusión, de dominio del no discernimiento. El lector - esto se ve acentuadamente en el presente- no distingue entre un fino trabajo sobre la norma y una tosca copia de la oralidad a la que considera "natural"; entre la operación lingüística de Nicanor Parra, sostenido en un rigor teórico duro - el de "lo común verdadero" (Stanley Cavell) 7 - y un trabajo tosco, "de oído", sin ningún rigor propositivo formal, de muchos "poetas comunicantes", nombre de una antología que Mario Benedetti publicó en 1972 y que incluía, como una especie de figura paradigmática, a Nicanor Parra. ${ }^{8}$ El no discernimiento es sólo un pálido eco de un lector que lee poesía mediado por la mediatización informática, ya sea en sentido positivo, huyendo de ella $-\mathrm{y}$ por lo tanto en peligro de hacer uso de la poesía como consuelo-, o bien bajo su influjo. No es posible leer poesía de un nivel óptimo bajo amparo de formadores de opinión. Se diría más radicalmente: no es posible leer poesía mediado. La operación que propo-

${ }^{6}$ Oswald de Andrade, "Manifiesto antropófago", en Jorge Schwartz, Las vanguardias latinoamericanas. Textos programáticos y críticos (Ciudad de México: Fondo de Cultura Económica, 2002), 171.

${ }^{7}$ Stanley Cavell, En busca de lo ordinario. Líneas del escepticismo y romanticismo (Madrid: Frónesis-Cátedra, 2002).

${ }^{8}$ Mario Benedetti, Los poetas comunicantes (Montevideo: Marcha, 1972). 
ne Parra va más allá de una necesidad popular de escapar de lenguajes elitistas vanguardistas o postvanguardistas. Entronca con poéticas decimonónicas vinculadas al simbolismo como el citado caso del uruguayofrancés Jules Laforgue en primerísimo lugar, pero también, aunque por vía indirecta y tal vez contradictoria, con el Mallarmé de la formulación inscrita en su célebre soneto "En la tumba de Edgar Allan Poe": "hay que dar un sentido más puro a las palabras de la tribu" ("il faut donner en sens plus pur aux mots de la tribu"). ${ }^{9}$ Las "palabras de la tribu" no son las palabras del poema. Las palabras del poema son ya "el sentido más puro" de las palabras de la tribu para Mallarmé. Hay una conversión, un destilado, un espulgue de todo lo in-esencial de la palabra poética. Pero siempre, para Mallarmé, el concepto de palabra poética está tomado como palabra específica, no común. Y tampoco se implica que la palabra común atesore algún tipo de perla rara — esto es, de especificidad oculta - que se trata de revelar. La tarea poética es producto de esa alquimia transformadora que permite convertir lo bruto en joya. Parra pretende una operación similar, sobre todo si se comprende la política de Poemas y antipoemas, una política de careo - falso careo a veces - que busca enfrentar lo que pertenece a la zona del poema - una zona muy trabajada, es verdad, con un extremo cuidado en el manejo de la concepción de lírica que evita cualquier caída en lo sentimental y en lo adjetival, considerados como modo de chantaje poético-literario- y lo que pertenece a la zona del antipoema, un paso más allá de una norma media que señalaría lo que es, todavía, una lírica manejada decorosamente. El equilibrio propuesto es ejemplar, en la medida en que el lector de poesía - esto es, especializado - logra identificar lo que puede ser lenguaje poético en el lenguaje hablado sin caer, y esto es de primerísimo orden en importancia, en el alto contraste ni en la caricatura -me refiero al uso del lenguaje, no a los "escenarios"- que se monta Parra para poner en actuación a su personaje antipoético. Para dar cabida al antipoema hay que haber trabajado con gran sutileza al poema. El antipoema no se propone como una reacción al lenguaje obsoleto del poema, ése ni siquiera está en consideración: se propone como un devenir de lo mejor del lenguaje poético, de lo más excelso, donde destaca la potencia de la ambigüedad.

\footnotetext{
${ }^{9}$ Stéphane Mallarmé, Oeuvres complètes (París: Galimard-Pléiade, 1945).
} 
3.

Una de las características del lenguaje poético de Parra es la dimensión de verdad extrapoética que abre. El poema tradicional -o "poema", en términos de la oposición parriana - es una caja cerrada en este sentido: protege lo que es su parte obra negra, sus "mecanismos constitutivos". Es el arte moderno el que comienza a deshacerse de su ocultamiento; a mostrar, desde un discurso paralelo (Mallarmé) o desde su misma interioridad a modo de una doble voz (Octavio Paz), lo que el poema tradicional quiere olvidar, eso que con Baudelaire - llámese "mal" al concepto completo en su caso- comienza a vislumbrarse como voluntad de completud: la(s) otra(s) cara(s) del poema. Lo que logra re-hacerse como entidad poema luego del desmantelamiento de la poesía de las tres primeras décadas del siglo XX, no lo hace únicamente con el olvido de la vanguardia; es decir, por un salto retrospectivo hacia una anterioridad vanguardista como si no hubiera habido lo que hubo. Lo hace apelando a esa verdad extrapoética. El poema habla así desde un lugar no poético o más allá del poema, en un acarreo hacia el discurso poético de esa cantidad de verdad de elaboración - resto, margen, residuo serían nombres con calidad de des-hecho, pero que también pertenecen a esta noción de verdad - que pasa, por expulsión, a ser considerada ajena. Nótese que llamo "verdad" a la dimensión material que configura al poema. El poema es una entidad que luchó a muerte o, mejor, con una muerte para protegerse de su propia materialidad, como quien se blinda ante una fuerza que parece proceder de un afuera pero que en realidad está dentro. Esa protección, paradójicamente, es la que permitió el nacimiento de la forma cerrada o forma de fachada cuyo ejemplo mayor es el soneto. Lo sorpresivo, el impacto parriano, reside en gran medida en la muestra de esa verdad que actúa secularmente como una revelación. Pero lo que es propio, único de Parra, es que extrae esa verdad de un lenguaje que no es el lenguaje poético como materia prima. La poeticidad de una tradición actúa en Parra como protección de su empresa. Su referencia a cierta topología caduca - "el poeta vate", "el poeta vaca sagrada", "la poesía de sombrero alón... espejismo del espíritu", etc.- oficia como amparo de una operación que no está en ese lenguaje. Lo dije: Parra actúa a lenguaje dado, no a invención de lenguaje. Lo que practica es una nivelación de ese lenguaje dado, una operación altamente distintiva porque significa 
trabajar en un espacio no considerado. Toda poesía es un sobrante desde la pregunta de Hölderlin en "Pan y vino": "¿Y para qué poetas en tiempos de penuria?". ${ }^{10}$ Esa pregunta, en vez de encerrar el "caso poético", lo abre infinitamente. Desde comienzos del siglo XIX la poesía ha intentado una y otra vez contestarla. Pero hay de sobrante a sobrante. Y el sobrante extrapoético es muy sobrante. El peligro aparece con la demanda post Segunda Guerra Mundial que cristaliza en la década de los sesenta del siglo pasado de hipervinculación, de sobrecomunicación, por el definitorio, para nuestra cultura, vehículo de la mediatización que juega con el espejismo de todas las cartas sobre la mesa. La espectacularización del mundo - la realidad vista como segunda naturaleza, como muestra Guy Debord ${ }^{11}$ — hace aparecer gratuitamente el fenómeno, lo que demarca el campo de todas las cosas. El mundo de todas las cosas vistas como mercancía, empezando por la carta de presentación de la mercancía: la vista, incluye la obscenidad, el "fuera-deescena", paradójicamente, como elemento nuclear. Esto tiende a anular cualquier revelación o trabajo de des-cubrir. A lo que llevaría, por lo contrario, es a un desesperado re-cubrimiento del lenguaje poético si el lenguaje poético, a esta altura, sigue siendo la conciencia del (lenguaje del) mundo. EP

${ }^{10}$ Friedrich Hölderlin, Las grandes elegías (1800-1801); versión castellana y estudio preliminar de Jenaro Talens (Madrid: Hiperión, 1966).

${ }^{11}$ Guy Debord, La sociedad del espectáculo (Valencia: Pre-Textos, 1999). 